\section{Investigating the role of vasopressin in anaphylactic shock}

Ulugbek Nurmatov and *Aziz Sheikh ${ }^{\mathrm{b}}$

\footnotetext{
a Research Fellow, ${ }^{\text {b }}$ Professor of Primary Care Research \& Development, Allergy \& Respiratory Research Group, Division of Community Health Sciences: GP Section, University of Edinburgh, UK
}

*Corresponding author: 20 West Richmond St, Edinburgh, EH8 9DX, Scotland, UK. Tel: +44 (0)131651 4151 Fax: +44 (0)131 6509119 E-mail: aziz.sheikh@ed.ac.uk

\section{Dewachter P, Raeth-Fries I, Jouan-Hureaux V, et al. A comparison of epinephrine only, arginine vasopressin only, and epinephrine followed by arginine vasopressin on the survival rate in a rat model of anaphylactic shock. Anesthesiology 2007;106:977-83.}

Parenterally-administered adrenaline (epinephrine) is the internationally recommended treatment of choice in anaphylaxis, ${ }^{1,2}$ but despite its prompt use some people still experience poor outcomes. ${ }^{3}$ There is, therefore, a need to investigate novel treatment options, but such studies are methodologically complex and ethically fraughtin the context of the management of an acute potentially life-threatening disorder. ${ }^{4}$ Animal studies can prove very helpfulan situations such as this, as has been the case, for example, with research investigating the optimum dose and timing of adrenaline in canine models of anaphylaxis. ${ }^{5,6}$

Dewachter and colleagues' new study in rats suggests that the combination of adrenaline and arginine vasopressin (AVP) may improve outcomes in anaphylactic shock, thus providing early evidence of a potentially new treatment approach.? The use of vasopressin has previously been proposed, but the evidence base in support of its use has been weak. ${ }^{8-11}$ In this study, the authors randomly allocated Brown Norway rats into four groups ( $n=6$ in each group). All rats were anesthetised and anaphylactic shock was induced. The rats then received treatment five minutes after the onset of anaphylactic shock with either: (i) saline ('no treatment' group); (ii) two boluses of adrenaline followed by continuous infusion (adrenaline group); (iii) AVP bolus followed by continuous infusion (AVP group); or (iv) adrenaline bolus followed by AVP continuous infusion (adrenaline+AVP group). The main outcome measure of interest was survival rate.

The authors found that in the 'no treatment' and AVP groups the survival rate was $0 \%$. In the adrenaline group, survival rate was $84 \%$. In the adrenaline+AVP group, survival was $100 \%$. These findings suggest that AVP used in isolation is unlikely to have a therapeutic role in the emergency management of anaphylaxis, but it could have a useful role to play if used in combination with adrenaline, although the numbers of rats studied were too small to conclude this with any reliability.

Future work now needs to replicate these findings in a larger study so as to ascertain more conclusively whether adding AVP to adrenaline offers any therapeutic advantage. If confirmed, this work should also aim to elucidate the causal mechanism through which this combination of adrenaline and AVP may be interacting to reverse the manifestations of anaphylactic shock.

\section{Conflict of interest declaration}

Professor Aziz Sheikh is an Assistant Editor of the PCRJ, but was not involved in the editorial review of hor the decision to publish, this article.

\section{References}

Alrasbi M, Sheikh A. Comparison of international guidelines for the emergency medical management of anaphylaxis. Allergy 2007;62:838-41.

2. Simons FER, Sheikh A. Evidence-based management of anaphylaxis. Allergy 2007;62:27-829.

3. Pumphrey RS. Lessons for management of anaphylaxis from a study of fatal reactions. Clin Exp Allergy 2000;30:1144-50.

4. Sheikh A, Ten Broek V, Brown SG, Simons FE. H1-antihistamines for the treatment of anaphylaxis: Cochrane systematic review. Allergy 2007;62:830-7.

5. Bautista E, Simons FE, Simons KJ, et al. Epinephrine fails to hasten hemodynamic recovery in fully developed canine anaphylactic shock. Int Arch Allergy Immunol 2002;128:151-64.

6. Mink SN, Simons FE, Simons KJ, Becker AB, Duke K. Constant infusion of epinephrine, but not bolus treatment, improves haemodynamic recovery in anaphylactic shock in dogs. Clin Exp Allergy 2004;34:1776-83.

7. Dewachter $P$, Raeth-Fries I, Jouan-Hureaux $V$, et al. A comparison of epinephrine only, arginine vasopressin only, and epinephrine followed by arginine vasopressin on the survival rate in a rat model of anaphylactic shock. Anesthesiology 2007;106:977-83.

8. Kill C, Wranze E, Wulf $H$. Successful treatment of severe anaphylactic shock with vasopressin. Int Arch Allergy Immunol 2004;134:260-1.

9. Schummer W, Shummer C, Wipperman J, Puchs L. Anaphylactic shock is vasopressin the drug of choice? Anesthesiology 2004;101:1025-7.

10. Dewachter P, Jouan-Hureaux V, Lartaud I, Bello G, de Talance N, Longrois D, Mertes PM. Comparison of arginine vasopressin, terlipressin or epinephrine to correct hypotension in a model of anaphylactic shock in anesthetised Brown Norway rats. Anesthesiology 2006;104:734-41.

11. Hiruta A, M itsuhata H, Hiruta M, Horukawa Y, Takeuchi H, Kawakami T, Saitoh J, Seo N. Vasopressin may be useful in the treatment of systemic anaphylaxis in rabbits. Shock 2005;24:264-9.

doi:10.3132/pcrj.2008.00048 